\title{
Integrating Renewable Energy Technologies and Thermal Energy Storage to Support Building Trigeneration Systems: A Multicriteria Approach
}

\author{
Eduardo Antonio Pina \\ Grupo de Ingeniería Térmica y Sistemas Energéticos (GITSE) \\ Instituto de Investigación en Ingeniería de Aragón (I3A) \\ Universidad de Zaragoza, Mariano Esquillor s/n, 50018, Zaragoza, Spain. \\ e-mail: epina@unizar.es
}

\begin{abstract}
The present work proposes a multi-objective optimization model to determine the optimal configuration and operation of trigeneration systems including renewable energy technologies (RET) and thermal energy storage (TES). The model minimises the total annual cost and $\mathrm{CO}_{2}$ emissions. Trade-off solutions between both objectives were obtained and different configurations were analysed.
\end{abstract}

\section{Introduction}

Trigeneration can be defined as the production of three energy services (e.g. electricity, heat, and cooling) from the same resource, as a result of appropriate process integration. In the design of trigeneration plants for buildings, two fundamental issues must be addressed [1,2]: the synthesis of the plant configuration (installed technologies and capacity, etc.) and the operational planning (operational state of the equipment, energy flow rates, etc.). This task is complicated by the wide variety of technologies commercially available and the great diurnal and annual fluctuations in energy demands and energy prices. Other factors that increase complexity are: (i) the incorporation of RET, characterized by low predictability and nonsimultaneity between production and consumption, (ii) the incorporation of TES, which allow to decouple production from consumption, and (iii) conflicting objectives, as the minimization of environmental burdens is often contradictory to the minimization of costs.

A Mixed Integer Linear Programming (MILP) model is proposed herein to determine the optimal configuration and operation of trigeneration systems considering the incorporation of RET (photovoltaic panels and solar thermal collectors) and TES (hot water and chilled water storage tanks). The objective functions to be minimised are the total annual cost and total annual $\mathrm{CO}_{2}$ emissions. The MILP model provides a Pareto Frontier, a set of solutions representing the optimal trade-offs between the economic and environmental objectives, in which there can be no increase in one objective without a decrease in the value of the other.

\section{Trigeneration system description}

The trigeneration system analysed herein must attend the electricity, heating, and cooling demands of a multifamily building complex located in Zaragoza, Spain. The energy demands and the operation of the system are characterized by 12 representative days (one for each month of the year), each divided into 24 consecutive periods of 1hour duration. The superstructure of the trigeneration system, presented in Figure 1, includes: a cogeneration module (GE, natural gas reciprocating engine coupled with a hot water heat recovery system), a gas boiler (GB), a reversible heat pump (HP), a single-effect absorption chiller (ABS), photovoltaic panels (PV), solar thermal collectors (ST), a hot water storage tank (TSQ), and a chilled water storage tank (TSR). The HP can operate in cooling mode (HPR) during the summer, and in heating mode (HPQ) for the rest of the year. All devices are commercially available. The system is connected to the electric grid, which allows for the purchase or selling of electricity.

The optimization procedure reduces the superstructure to its optimal configuration (installed technologies and their capacities). Also, the optimal operational strategy for each hour of each representative day is determined (charge/discharge of the TSQ and TSR, purchase/selling of electricity to the grid, purchase of natural gas, etc.). 


\section{Multi-objective optimization}

The MILP model was developed using the software LINGO [3]. The objective functions to be minimised (total annual cost and total annual $\mathrm{CO}_{2}$ emissions) are restricted to equipment constraints (capacity limits and production restrictions), energy balances, and electric grid constraints. Fixed (capital) and variable (operation) costs are considered.

First, single objective optimizations were performed to determine the optimal configurations of each of the objective functions. Then, the multi-objective optimization was carried out, obtaining the many trade-off solutions that constitute the Pareto Frontier presented in Figure 2, in which equal symbols represent the same configuration (with different installed capacities).

The extreme points $\mathrm{A}$ and $\mathrm{B}$ correspond to the single-objective solutions. As can be seen, the optimal cost configuration (A) includes all candidate technologies, except for the renewable ones (PV and ST); in the case of the optimal $\mathrm{CO}_{2}$ emissions configuration (B), both $\mathrm{PV}$ and ST devices are included, while the GE and TSR are kept out. Concerning the annual operation of both configurations: (i) A is significantly more dependent on natural gas than B (663.5 MWh/yr and 0.1 $\mathrm{MWh} / \mathrm{yr}$, respectively); and (ii) $\mathrm{A}$ is less dependent on purchase of electricity than B (250.6 MWh/yr and $354.9 \mathrm{MWh} / \mathrm{yr}$, respectively). Configuration C was the trade-off solution selected because it presents a $36 \%$ reduction in $\mathrm{CO}_{2}$ emissions and a 9\% increase in total economic cost relative to $\mathrm{A}$. This configuration includes PV, but does not include a GE.

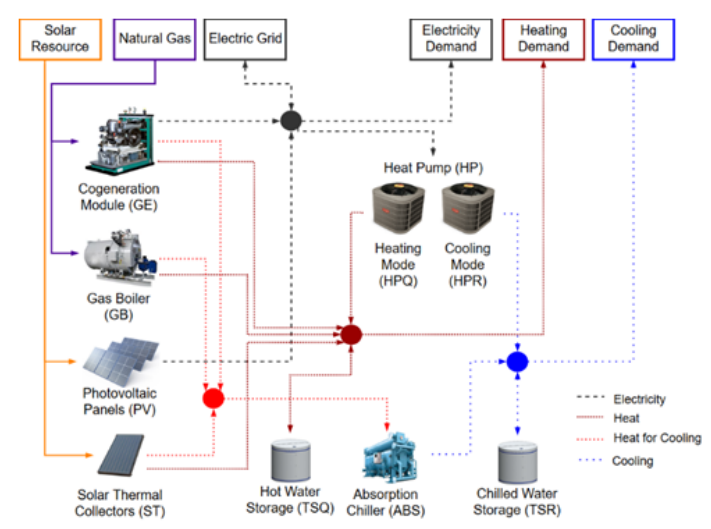

Figure 1. Trigeneration system superstructure.

\section{Conclusions}

The procedure developed in this paper showed that the trajectory between one single objective solution to the other is not linear. From the optimal cost solution, as $\mathrm{CO}_{2}$ emissions are forced down, the model reshapes the system, defining intermediate solutions with different configurations and operation modes. Therefore, the Pareto Frontier was essential to identify trade-off solutions with reasonable sacrifices to both objective functions. In particular, solution $\mathrm{C}$ achieved a $36 \%$ reduction in $\mathrm{CO}_{2}$ emissions relative to the optimal cost configuration with a 9\% increase in total costs. This proved that it is not necessary to go all the way to the single objective solutions to achieve interesting results.

In order to properly carry out this analysis hourly electricity prices and the associated hourly $\mathrm{CO}_{2}$ emissions are essential. However, for Spain the $\mathrm{CO}_{2}$ emissions are provided by the IDAE only on a yearly basis. By simplifying part of these data to yearly averages, the model is moved further from reality and will probably miss configurations and operational strategies that bring more interesting results.

\section{REFERENCES}

[1] LOZANO, M.A., CARVALHO, M., and SERRA, L.M. Allocation of economic costs in trigeneration systems at variable load conditions. Energy and Buildings. 2011, 43(10), 2869-2881.

[2] WAKUI, T., KAWAYOSHI, H. and YOKOYAMA, R. Optimal structural design of residential power and heat supply devices in consideration of operational and capital recovery constraints. Applied Energy. 2016, 43(10), 118133.

[3] SCHRAGE, L. Optimization modeling with LINGO. Lindo Systems, 1999.

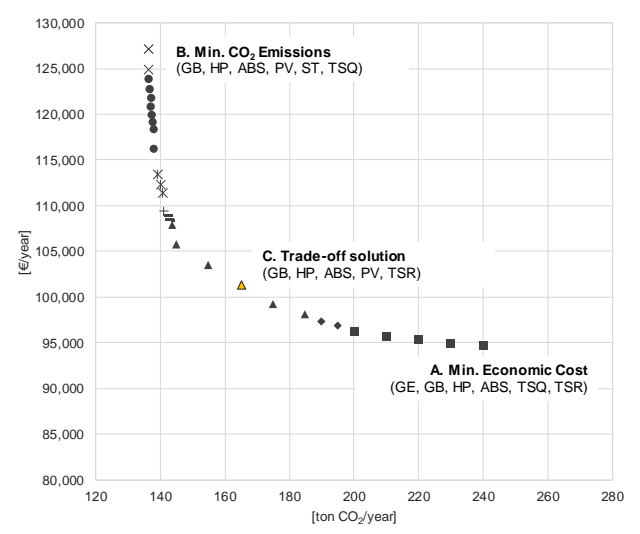

Figure 2. Pareto Set: Economic cost vs. $\mathrm{CO}_{2}$ emissions

Revista "Jornada de Jóvenes Investigadores del I3A", vol. 5 (Actas de la VI Jornada de Jóvenes Investigadores del I3A - 2 de junio de 2017). ISSN 2341-4790. 